La revue La revue pour l'histoire du CNRS

POUR L'HISTOIRE DU CNRS

$14 \mid 2006$

Le patrimoine scientifique

\title{
Mythes et histoire des sciences humaines
}

Laurent Mucchielli. Paris, La Découverte, Collection « Recherches », 2004

François Vatin

\section{(2) OpenEdition}

Journals

Édition électronique

URL : https://journals.openedition.org/histoire-cnrs/476

DOI : $10.4000 /$ histoire-cnrs.476

ISSN : 1955-2408

Éditeur

CNRS Éditions

Édition imprimée

Date de publication : 3 mai 2006

ISBN : 978-2-271-06350-2

ISSN : $1298-9800$

Référence électronique

François Vatin, "Mythes et histoire des sciences humaines », La revue pour l'histoire du CNRS [En ligne], 14 | 2006, mis en ligne le 07 mars 2006, consulté le 20 mai 2021. URL : http://

journals.openedition.org/histoire-cnrs/476 ; DOI : https://doi.org/10.4000/histoire-cnrs.476

Ce document a été généré automatiquement le 20 mai 2021

Comité pour l'histoire du CNRS 


\section{Mythes et histoire des sciences humaines}

Laurent Mucchielli. Paris, La Découverte, Collection « Recherches », 2004

\section{François Vatin}

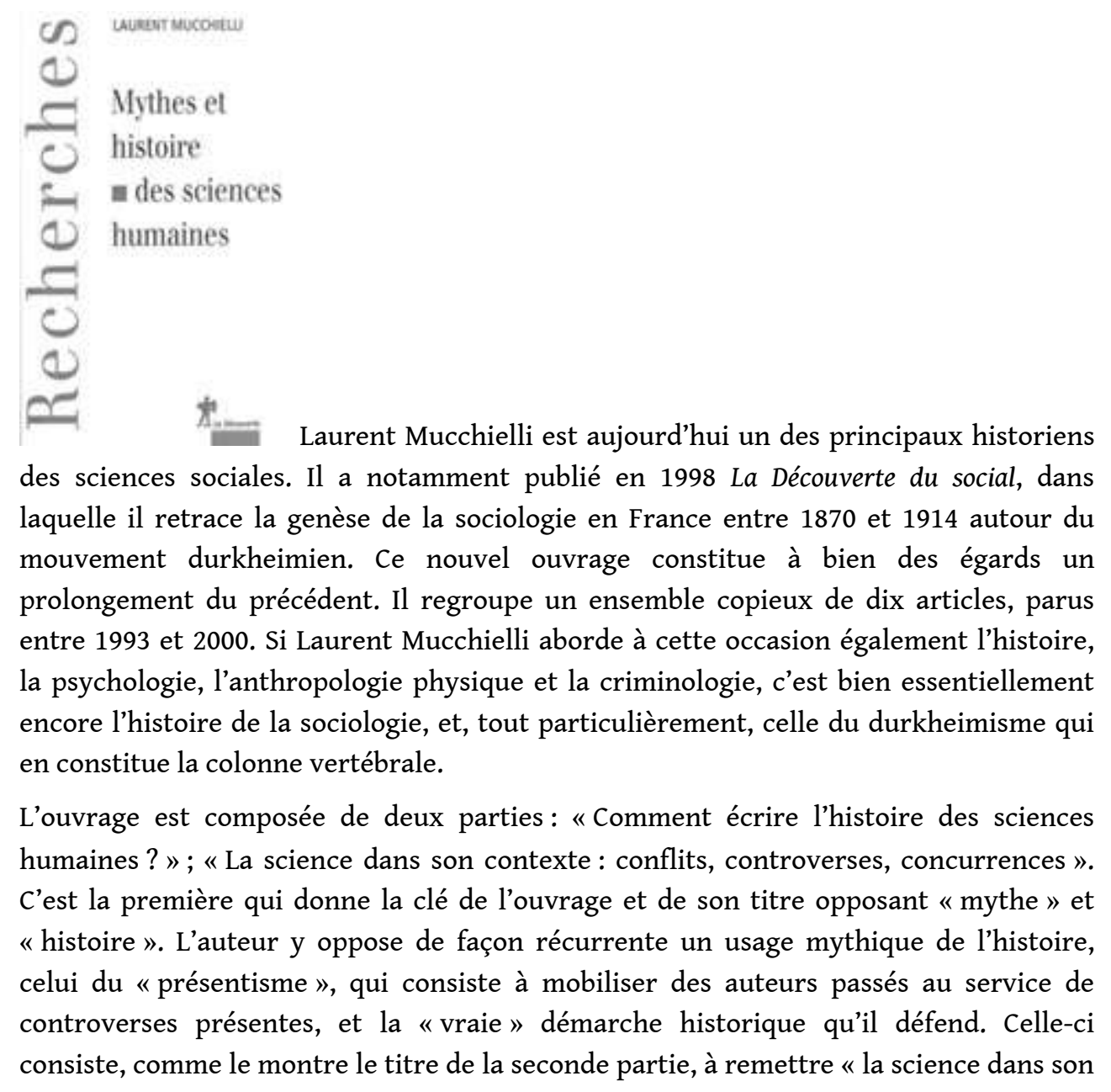


contexte ", épistémologique, mais aussi social et politique (l'importance de l'affaire Dreyfus dans l'histoire du durkheimisme), académique (comment se jouent les luttes d'influence dans un champ scientifique donné à une époque donnée), voire psychologique (voir l'étude sur la psychologie de Durkheim qui fournit le dixième et dernier chapitre de l'ouvrage).

2 Nous partageons largement cette critique du présentisme en histoire des sciences. Par ailleurs, Laurent Mucchielli possède une grande érudition et un indéniable talent d'écriture, un art de raconter l'histoire, qui fait que son livre n'est jamais ennuyeux, ce qui est une qualité rare. Voilà donc de bonnes raisons de lire cet ouvrage, où on apprendra beaucoup, paradoxalement d'ailleurs plus à notre sens sur les marges de la sociologie durkheimienne (l'école historique positiviste de la fin du XIX ${ }^{e}$ siècle ou la psychologie de Charles Blondel) que sur celle-ci proprement dite. Toutefois, dans sa conception générale, l'ouvrage peut laisser le lecteur insatisfait et, à notre sens, ne sert finalement pas bien la cause que l'auteur entend défendre.

Il y a d'abord une question de "ton». Laurent Mucchielli a souvent tendance à "donner des leçons », comme lorsqu'il fustige (p. 30) les "apprentis-historiens » (i.e. " de Raymond Aron à Raymond Boudon »!). Il prétend régulièrement «faire sortir de l'oubli » (p. 93) des auteurs comme si personne avant lui ne s'était intéressé à eux. Ainsi (p. 116), il dit que l'historien Henri Sée aurait « sombré dans l'oubli » (pas à Rennes en tout cas, où un amphithéâtre porte son nom). De même (p. 150), Maurice Halbwachs est présenté comme un sociologue « dont le nom était presque oublié jusqu'à ces dernières années ", ce qui nous paraît être un énoncé pour le moins audacieux, quand on sait l'influence qu'il exerça sur Georges Friedmann, Paul-Henri Chombart de Lauwe ou Pierre Bourdieu. La question n'est toutefois pas ici de débattre sur le mode proposé par l'auteur, mais de contribuer à la discussion du " présentisme » qu'il engage. Sans doute, souvent, ses critiques tombent juste, comme quand il montre les ressorts de la «redécouverte» périodique de Gabriel Tarde (chapitre 2) ou ceux de l'opposition académique entre durkheimisme et weberisme (chapitre 3). Mais de telles critiques ne peuvent-elles pas être adressées parfois aussi à ses propres analyses? L'histoire n'est jamais neutre ; elle est, quoi qu'on en veuille, toujours écrite au présent. Le sociologue est bien placé pour savoir que toute étude (historique ou autre) est "biaisée »; le problème n'est pas de supprimer les biais, projet d'un positivisme un peu naïf, mais de les reconnaître pour n'en être pas trop dupe.

4 En l'occurrence, comme celle des auteurs qu'il critique, l'histoire des sciences sociales de Laurent Mucchielli est militante. Comment d'ailleurs s'en étonner de la part d'un auteur qui s'est fait connaître par ailleurs par des travaux très militants en sociologie criminelle? Dans ce livre, comme d'ailleurs dans celui de 1998, il défend la tradition durkheimienne et ses cibles privilégiées sont les « libéraux » et les adeptes, présents ou passés, d'un réductionnisme biologique. Le simple examen de l'index témoigne à lui seul sans ambiguïté de la place de Durkheim et de ses disciples dans son panthéon théorique. Nous ne lui reprochons pas ce penchant. Mais il le conduit parfois à des abus. Ainsi, alors que sont présentées (au chapitre 6) les critiques de Bouglé et d'Hubert contre l'anthropologie raciale comme « scientifiquement » fondée (au sens des sciences de la nature) - ce que nous ne discutons pas -, Blondel ferait en revanche usage d'un "argument d'autorité » (p.246) dans sa critique de l'interprétation de l'aphasie par Halbwachs, en rappelant que, sur ce point, les travaux des neurologistes concluent sans 
ambiguïté à l'existence de lésions cérébrales, ce qui ne nous paraît guère plus discutable.

Par sa richesse et sa qualité, l'ouvrage de Laurent Mucchielli a indiscutablement sa place dans la bibliothèque d'histoire de la sociologie française qui n'est pas si considérable. Il est très utile notamment par les ouvertures qu'il propose sur l'histoire et la psychologie. Mais on peut s'étonner de ce que l'auteur se présente comme un novateur radical parcourant des champs inexplorés alors que l'essentiel de son investigation porte sur le durkheimisme qui reste assurément le courant le plus étudié, et de loin, de l'histoire des sciences sociales françaises. Pour développer, selon ses vœux qui sont aussi les nôtres, une vraie histoire "contextuelle » des sciences humaines, il nous semble qu'il y aurait bien d'autres auteurs et courants de pensée à l'étude desquels Laurent Mucchielli pourrait offrir les services de son talent et de son érudition indéniables.

\section{AUTEUR}

\section{FRANÇOIS VATIN}

Professeur, membre de l'UMR IDHE 